\section{LAURENCE - MOON - BIEDL SYNDROME}

BY

GRAHAM H. ANDERSON, M.B., Ch.B., F.R.F.P.S.G.

The association of retinitis pigmentosa with polydactylism was recorded in 1860 by Laurence and Moon and the Fröhlich syndrome in 1901. Biedl in 1921 described the pentad of polydactylism, obesity, hypogenitalia, retinitis pigmentosa, and mental retardation, with a familial occurrence ; the association being now known as the LaurenceMoon-Biedl syndrome. Variants have also been described by Biesmond, Van Bogaert, and by Delhaye in which coloboma of the iris replaced the retinal degeneration. Graefe in 1866 described optic atrophy as complicating oxycephaly, but not of the pigmentary degenerative type (Duke-Elder, 1940; Ridley and Sorsby, 1940). Mann (1937), however, records oxycephaly as one of the skeletal abnormalities which may be present with the syndrome.

Retinitis pigmentosa occurs much more often as an isolated disability than in combination with other disabilities. Nettleship worked out many pedigrees in which there was no other defect. Usher obtained similar results when searching especially for combined defects. In the Eugenics Laboratory Memoirs (1922) is reported a series of 914 cases, in 656 of which the patients suffered from retinitis pigmentosa alone. Deaf-mutism, or mental deficiency, occurred in 96 cases $(10.41 \%)$, and was the commonest associated affliction. In only 9 cases (less than 1\%) was polydactylism noted; such a combination is therefore rare. The genealogical tables constructed showed that retinitis pigmentosa could apparently be transmitted as an inherited Mendelian dominant, or recessive, or sex-linked character, whereas the Laurence-Moon-Biedl syndrome occurred as a recessive Mendelian type (Eugenics Laboratory Memoirs, 1922).

Pathological evidence of pituitary abnormality has generally been indefinite and disappointing. Dax (1938), however, reported the presence in the blood and urine, but not in the cerebrospinal fluid, of a substance which was melanophore-expanding in frogs and caused a visible darkening of the skin on injection. This substance could be demonstrated in cases of retinitis pigmentosa, with or without other abnormalities. It was also present in conditions of known pituitary stress, such as pituitary tumours, hyperthyroidism, and pregnancy. Similarly prepared extracts from healthy controls or other endocrinal upsets did not contain this substance. The presumption of a hypophysialdiencephalic lesion has thereby gained some experimental justification, but vascular phenomena, according to earlier Italian workers, also play an important part in the pigmentary degenerative process (Dax, 1938).

\section{Case Report}

A spinster, aged 45, was admitted to ward 2 of the Western Infirmary, Glasgow, complaining of severe headaches occurring at frequent intervals over a period of two years. At birth rudimentary sixth digits were present on each extremity, but these spontaneously wasted and disappeared during her infancy. Soon after attending school she discovered her eyesight was defective, the defect being more pronounced at night. Ophthalmological examination at this time led to a diagnosis of retinitis pigmentosa. She had always been a fat child but less than average in height, and at the age of 11 she weighed 13 st. $(82.5 \mathrm{~kg}$.). Menstruation began when she was 13 , a regular $4 / 28$ day cycle continuing up to the time of writing.

Eczema first appeared at the age of three months and asthmatic attacks when she was four years old. Both have occurred intermittently throughout her life. Two years before admission she began to suffer from headaches, usually present on waking but sometimes developing later in the day. The occipital region was generally affected, with occasional spread over the vertex and forwards to the frontal area. They were not accompanied by nausea, vomiting, or any increased visual disturbance, nor were they induced by those foods which she had learned by experience to regard as provoking attacks of eczema or asthma.

On examination the patient was seen to be obese, but not grossly so. Her face was florid, with marked hirsutism but no congested veins. Her skin was dry and scaly, with one small weeping area on the dorsum of the hand. Small scars were present at the lateral bases of the fifth digits. Her skull was of a pronounced oxycephalic shape. Her weight was $12 \mathrm{st} .11 \mathrm{lb}$. $\left(81.2 \mathrm{~kg}\right.$.), her height $5 \mathrm{ft} .4 \frac{1}{2}$ in. $(1.64 \mathrm{~m}$.).

Clinical and $x$-ray examination of the lungs was compatible with the asthmatic history. The blood pressure was $175 / 105$ $\mathrm{mm} . \mathrm{Hg}$. Clinical and special methods of examination revealed no other abnormalities in the cardiovascular system. Blood examination showed: $\mathrm{Hb}, 75 \%$ (Sahli) ; red cells, 3,800,000 per c.mm.; white cells, 6,800 per c.mm.; films-normal cell pattern; normal sugar-tolerance curve-fasting, $0.100 \%$; half hour, $0.170 \% ; 1$ hour, $0.180 \% ; 1 \frac{1}{2}$ hours, $0.100 \% ; 2$ hours, $0.090 \%$. No sugar in the urine, nor was any chemical or microscopical abnormality detected. Average daily volume was $49 \mathrm{oz}$. (1.39 litres). Average daily excretion of 17-ketosteroids was $3.7 \mathrm{mg}$. (average normal, $13 \mathrm{mg}$. with limits $4-23 \mathrm{mg}$. ; Hadfield and Garrod, 1947). The B.M.R. was $-19.5 \%$. Examination of the C.S.F. showed : pressure, normal ; cells, 2 per c.mm.; Wassermann reaction and colloidal gold tests (Lange), negative ; no precipitation to Pandy's or Nonne Apelt tests. Hearing was normal with both ears. Sight : large objects seen at $6 \mathrm{ft}$. $(1.83 \mathrm{~m}$.) but without definition; individuals not recognized close up ; strong contrast colours distinguished close up. Fundi : peculiar degeneration and pigmentary deposits of retinitis pigmentosa. No papilloedema or changes in vessels. Radiographs revealed that the pituitary. fossa was smaller than usual, that there was no bony abnormality, that the middle phalanges of both fifth fingers were "dumpy," and that there were rudimentary accessory digits at both fifth toes.

Intellect:-The patient was alert and quickly recognized voices. Her interests were limited, but this was clearly the result of her defective vision and not due to any mental defect. Her knowledge and understanding of everyday events, as reported on the radio, was quite up to normal standards.

She could not trace back any relative with blindness or polydactylism. There has been no Jewish racial mixing in the family so far as she is aware. No abnormality was found on examination of her mother and sister, the only relatives available.

\section{Discussion}

The above case is incomplete in two respects. Mental retardation was not an obvious feature, and amenorrhoea, which would be anticipated with hypogenitalism, was not present, an average normal menstrual cycle occurring during the patient's stay in hospital. The hirsutism was limited to the face and did not encroach on the male distribution of trunk and arms. The possibility of virilism (adreno-genital or pituitary basophilism) is further negatived by the low excretion rate of urinary androgenic (ketosteroid) substances. Such low values are obtained in hypopituitarism.

A benign myxoedematous state, induced by inadequate stimulation of the pituitary to the thyroid gland, readily affords an explanation of the lowered metabolic rate and anaemia. Hypertension is not uncommon in myxoedema, and the headaches symptomatically conform to the pattern associated with increased blood pressure. I have not traced an association with eczema and asthma in previous cases; thus an unlucky coincidence seems to have occurred in this patient's case.

The failure to elicit a family history is not surprising in a Mendelian recessive type, as several generations may elapse in human inheritance before suitable conditions (absence of a neutralizing dominant or other less easily explained factor) occur. An isolated case cannot therefore 
be assumed, but only that previous members of the family showing this syndrome have been buried even beyond the knowledge and memory of those still alive. Sufferers from this syndrome are of course unlikely to marry, and even if they do so are unlikely to have children-a factor which of itself curtails the passing on of the defective gene except as a latent recessive type.

My thanks are due to Dr. D. K. Adams for permission to publish this report.

\section{REFERENCES}

Dax, E. C. (1938). Trans. Ophthal. Soc., 58, 227.

Duke-Elder, W. S. (1940). Textbook of Ophihalmology, 3, 2768. London.

Eugenics Laboratory Memoirs (1922) (Nettleship Memorial Volume), 2, Part I. London.

Hadfield, G., and Garrod, L. P. (1947). Recent Advances in Pathology. London.

Mann, I. (1937). Developmental Abnormalities of the Eye, p. 193. Cambridge.

Ridley, F., and Sorsby, A. (1940). Modern Trends in Ophihalmology, p. 148 . London.

\section{Medical Memoranda}

\section{A Fatal Case of Solanine Poisoning}

Of the Solanaceae, A. belladonna (deadly nightshade) has long been recognized as having very poisonous properties owing to the high content of atropine in the plant. The commoner members of the nightsihade genus- $S$. dulcamara (woody nightshade) and $S$. nigrum (black nightshade)-are generally regarded as being harmless, although the alkaloid solanine has been recovered from the berries of these plants and has been shown to have toxic properties in experimental animals and to a less extent in human beings. We can trace only one authenticated case of death following ingestion of the red berries of the woody nightshade and one fatal case of black nightshade poisoning (Taylor, 1875).

\section{CASE Record}

A female child aged 9 years was admitted to hospital on the evening of Aug. 13, 1948, suffering from vomiting, abdominal pain, and distressed breathing. Her home was on the outskirts of a town and she was apparently in the habit of eating berries from hedges and from the embankment of a disused railway near her home. She had eaten berries on several occasions during recent weeks, the last occasion being three days before admission. The following day she had felt unwell but had improved. On the day before admission she had been taken ill with vomiting and had vomited "coffee-ground" material four times during the five hours before admission.

The child responded weakly to questioning and complained only of abdominal pain and thirst. She looked exhausted, the skin was pallid and dry, the expression anxious. There were slight restless movements of arms and head. She was not delirious. A feature which remained marked throughout was dyspnoea. Inspiration was short and gasping; expiration was prolonged and active and accompanied by a sigh. The respiratory rate was 32 per minute.

The pupils were of normal size and reacted to light. Although the child was dehydrated the tongue was moist. Examination of chest and abdomen revealed nothing of significance. The extremities were warm. There was neither paraesthesia nor paralysis. Temperature $96.4^{\circ} \mathrm{F} .\left(35.8^{\circ} \mathrm{C}\right.$.), pulse rate 140 per minute, blood pressure $120 / 88$.

A provisional diagnosis of vegetable irritant poisoning with central effect on the nervous system was made, and treatment was immediately instituted. This included stomach lavage, soap and water enemas, nikethamide $1.7 \mathrm{ml}$. hourly, and latterly oxygen. Fluids were given by mouth and per rectum. Some improvement in her general condition was maintained for 24 hours, but she later became weaker and more cyanosed and her respirations became very feeble. Death occurred in the morning of Aug. 15, 1948.

A post-mortem examination was carried out two hours after death. The main feature was an acute inflammation of the mucosa of the stomach and intestines, the inflammation decreasing in intensity towards the distal coils of small intestine and caecum. There were small haemorrhages in the mucosa of stomach and jejunum. The stomach contained about 1 pint $(568 \mathrm{ml}$.) of dark brown fluid, and dark greenish-brown semi-solid material was present in the upper coils of jejunum. The bowel contents decreased in amount and became paler towards the distal end of the small intestine. The contents of the colon were normal in appearance. Small fragments of the skin of a berry were found microscopically. The rectum was empty. Other abdominal organs appeared healthy. Thoracic organs, with the exception of the lungs, which were congested and oedematous, appeared healthy. The brain was normal in appearance.
Microscopically the liver showed moderate fatty infiltration and necrosis.

The post-mortem findings were regarded as being consistent with death from respiratory failure following the ingestion by mouth of some poisonous substance, and specimens of stomach and intestinal contents and liver were submitted for analysis. No alkaloid was found in the liver by the normal Stas-Otto process. A special search was made for solanine, and from about one-third of the liver $7 \mathrm{mg}$. of crude alkaloid was isolated, which on recrystallization from alcohol gave a product giving characteristic tests for the solanine complex.

A search at the place where the child played revealed the presence of masses of woody nightshade entangled with blackberries. The child's symptoms, the finding of solanine in this organ and the presence of much woody nightshade where the child played provide evidence that death was almost certainly due to poisoning by Solanum dulcamara.

\section{Discussion}

Fatal cases of solanine poisoning are very rare, and although much work has been done on the potato as a source of the poison very little appears in the literature concerning the other two common sources, Solanum dulcamara and Solanum nigrum. It is known that the potato varies greatly in solanine content with the season of growth. Abnormally wet summers appear to favour high alkaloidal content. It appears possible that Solanum dulcamara may be subject to similar variations and that this abnormally wet summer may have favoured high toxicity of the berries. Recorded cases suggest that some individuals may be abnormally sensitive to solanine.

According to Reil (1857) solanine destroys life by producing paralysis of the muscles of the chest. It is a slow-acting poison, and so far as we know has not yet been isolated from the vomit or stomach washings of suspected cases. It differs from atropine (deadly nightshade) and hyoscyamus (henbane) in not producing stupor or delirium, dilatation of the pupils, sphincter paralysis, or pyrexia.

Plants of the genus Solanum can be identified only by a botanical examination of the leaves and berries. The following brief accounts are extracted from Bentham and Hooker (1945).

“(1) Solanum dulcamara. Synonyms : Bittersweet, woody nightshade, felonwort, violet bloom, scarlet berry. Found commonly in hedges and thickets in moist shady situations all over Europe except the extreme north. Common in England and Ireland. Rare in Scotland. Stem shrubby at base, with climbing or straggling branches, often many feet in length. Leaves stalked, ovate or ovatelanceolate, two or three inches long, usually broadly cordate at the base and entire, but sometimes with an additional lobe or segment on each side. Flowers rather small, purple or blue with yellow anthers, in loose cymes, on lateral peduncles shorter than the leaves. Flowers in summer. Berries small, globular or ovoid and red when mature."

“(2) Solanum nigrum. Synonym: black nightshade. One of the most widely spread weeds. Common in England but local in Scotland and Ireland. An erect annual or biennial with very spreading branches, about a foot high. In Britain usually glabrous. Leaves stalked, ovate with coarse angular teeth. Flowers small and white in little cymes almost contracted into umbels on short, lateral peduncles. Berries small, globular, black."

R. F. Alexander, M.B., B.S.

G. B. Forbes, M.B., Ch.B.

E. S. Hawkins, O.B.E., B.Sc., A.R.C.S., F.R.I.C. REFERENCES

B entham, G., and Hooker, J. D. (1945). Handbook of British Flora. Ashford. Reil (1857). J. Toxicol., 2, 245 .

Taylor, A. S. (1875). On Poisons in Relation to Medical Jurisprudence. London.

\section{Five Cases of Belladonna Poisoning}

On Sept. 2, 1948, at 10.30 a.m., three children, Rosemary and Elizabeth, aged 7, and John, aged 8, were admitted to St. Mary's Hospital, Portsmouth, with the statement that during the night they had become delirious, lost the use of their legs, and could not see. All three were extremely restless on admission, twisting about, plucking at the bedclothes, and constantly grimacing. John and Rosemary were extremely talkative and obviously hallucinated; their speech was a little slurred. Elizabeth appeared to have some photophobia and lay with her head buried in the pillow, fiercely resisting any interference. All three children had hot, dry skins and a marked malar flush. The lips were dry and fissured, the pupils widely dilated and inactive to light. They had rapid pulses, 120-130, but normal temperatures and respiratory rates. The highest B.P. recorded was John's, $138 / 80 \mathrm{~mm}$. Hg. Lying in bed there was no obvious muscular incoordination, though they continuously executed purposeless movements. All deep reflexes were brisk. The following facts were elicited from the mother.

The patients and another brother had gone out to play in the park the previous afternoon. They returned home about 5 p.m. stating 